\title{
Role model: Deborah Gill
}

\section{Jacqui Wise speaks to Deborah Gill, professor of medical education and director of University College London Medical School}

\author{
Jacqui Wise
}

London

Deborah Gill is thrilled that she is now responsible for the leadership and strategic direction of UCL Medical School-the place where she was once a student herself. She laughs that, at an alumni event, she was told she was probably the person they least expected to hold such a role.

"I was quite a late developer. I blossomed later. I wasn’t a brilliant medical student." But she feels that being "pretty average" helps her understand the students' perspective. "I tell students it's OK to be top of the class but it's also OK to be one or two percent over the pass mark. It takes an awful lot of qualities to be a good doctor and not all those are about academic brilliance," she says.

Gill is a moderniser and introduced a new curriculum programme at UCL following her appointment as director in 2014. "It wasn't a very modern programme, we were very teacher centred," she says. "We have now introduced a more integrated programme, learning the right things at the right time from the right person. Early patient exposure and maintaining a patient focus in all learning was important."

She also introduced a lot of peer assisted learning. "There was resistance initially. It was thought to be a risky thing to do. But it is important to break down barriers and create a culture where senior students help junior students."

She has focused not only on improving the educational experience of the students but also their general experience. "So they feel they are part of a family which supports them." She still lectures and is also a personal tutor as she wanted to stay connected with students.

Gill feels in many ways that the student experience is the same today as it was during her time at medical school. "The biggest difference is to do with money. It is very financially challenging now to go to medical school- the enormity of debt is huge - and this excludes certain groups of people. The level of competitiveness has also increased. In my day it was more collaborative-it was about getting over the bar together."

One of her next goals is to widen the range of people who go to medical school. This includes looking at different admission criteria for disadvantaged students, scholarships, bursaries, and tailored support.

Another future project is to bring alumni and students together. "They have an enormous amount to give, such as networking, moral support, and showing the range of careers that are available," she says.

Gill was the first member of her family to go to university. After qualifying in medicine in 1990 at Middlesex Hospital Medical School (which became part of UCL) she went on to do general practice training at Northwick Park. "I didn't much like doctors and didn't enjoy hospitals at all. I went into general practice as it meant I could spend time with patients and have a more controlled exposure to other doctors."

Gill was then selected for the London academic training scheme which combined general practice training with working in academic general practice at Bart's medical school. "There I got bitten by the academic bug," she says.

At Bart's she worked on a project aimed at tackling the problem of retention of GPs in London. She then transferred to the Royal Free Medical School in London and continued developing and innovating in medical education. She managed to combine academic work with general practice and still works every Friday as a GP in Enfield. "It keeps me grounded. I still enjoy general practice but just couldn't do it every day," she says.

Gill says she was fortunate to have Jane Dacre (president of the Royal College of Physicians) as her mentor while at medical school and she encouraged her to apply for the post at UCL. "She is a wonderful female role model. She convinced me I could make it to the top."

\section{Nominated by Ahmed Rashid}

Deborah Gill is a world leader in medical education but what sets her apart is her unwavering commitment to improving the quality of training for her students and providing a supportive environment for her staff.

She is a genuine moderniser and is not afraid to make brave decisions or stand up for the values that she believes in. Through this dedication, she demonstrates that medical education, like medical practice, is first and foremost about compassion and care.

Ahmed Rashid is a GP in London and a senior clinical teaching fellow at University College London 


\section{Figure}

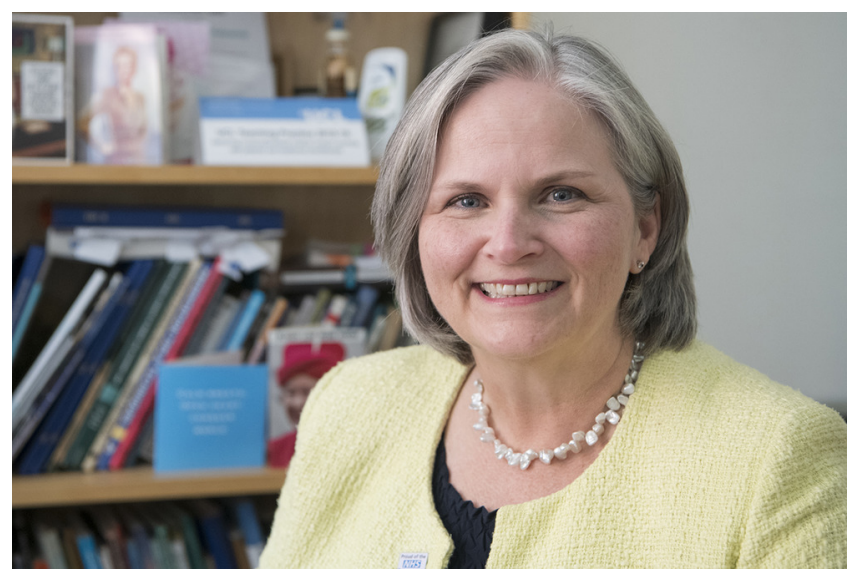

